\title{
Tribute to Jean-François Narbonne
}

\author{
Larry Robertson • Philippe Garrigues
}

Received: 5 February 2014 / Accepted: 11 February 2014 / Published online: 15 March 2014

(C) Springer-Verlag Berlin Heidelberg 2014

\section{Laudation by Larry Robertson}

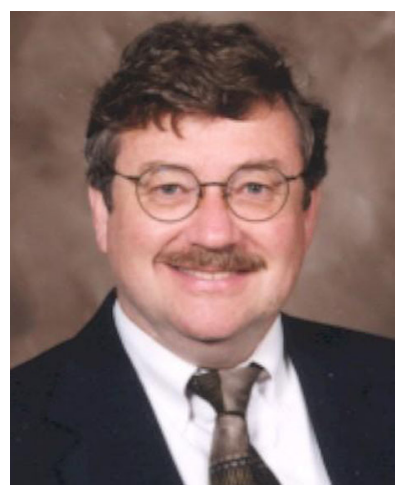

Jean-François, in celebration of your long and successful career in teaching and research in areas of nutrition and toxicology and at the completion of a highly successful seventh International PCB Workshop, held on May 27-31, 2012 in Arcachon, France, I offer you my hearty congratulations on the occasion of your retirement.

A quick look at your citations in PubMed shows your considerable productivity, starting in 1972 with a publication about "Starvation and re-feeding in carp" and quickly evolving to topics about vitamin A deficiency, PCBs, nutritional

Responsible editor: Philippe Garrigues

\section{Robertson}

Department of Occupational and Environmental Health, College of Public Health, The University of Iowa, 100 Oakdale Campus, Iowa City, IA 52242-5000, USA

e-mail: larry-robertson@uiowa.edu

\section{P. Garrigues $(\square)$}

Institut des Sciences Moléculaires, CNRS, UMR 5255, Université de Bordeaux, 33405 Talence Cedex, France

e-mail: p.garrigues@ism.u-bordeaux1.fr imbalances, the metabolism and effects of pesticides, and many more. These efforts reflect your broad interest in basic research and formed the basis of your service in EU regulatory panels and in national agencies. Last but not least, your book "Sang pour Sang Toxique" made the concepts of toxicology accessible to the broad French-speaking public.

Our long personal and professional association began in the early 1980s, as I was a Humboldt fellow in the laboratory of Professor Franz Oesch in Mainz and you were a professor in Bordeaux. You were engaged in cooperation with the Oesch laboratory that we expanded into a fruitful collaboration that resulted in over a half dozen of research publications and in the successful training of several doctoral and postdoctoral students. It also resulted in over 30 years of friendship and exciting discussions.

You were a regular participant in the PCB workshops, from the first one in Lexington, Kentucky, in 2000 to the one in Arcachon, always bringing a fresh perspective. Appreciated was not only your scientific expertise but also the passion with which you are fighting for a healthier environment and food supply. Your oral presentations and the following discussions which often lasted into the night are wonderful memories for many of us.

Aside from science, your other talents, as a tour guide, as a culinary expert, and as an entertainer, were evident at the Arcachon meeting and added enjoyment. It showed that it is possible to be at the same time an engaged scientist and a wellrounded person.

For the past year, you and I and many other researchers globally were together again in France, this time for a reevaluation of the carcinogenicity of PCBs. The result of that evaluation was an upgrading of PCBs to group 1 (human carcinogen) (Lauby-Secretan et al. 2013). The highly successful Arcachon PCB Workshop and the intense hard work of the IARC monograph meeting were fitting conclusions to a career involved in basic research, risk evaluation, and policy 
formulation. I am sure that we will see and hear more from you, since civil engagement does not stop with retirement, and we are looking forward to seeing you again and to more discussions, wherever in the world this may be.

\section{Laudation by Philippe Garrigues}

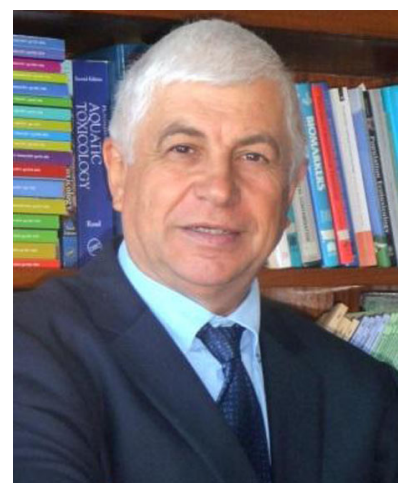

I met Jean-François Narbonne for the first time in the early 1980s in a swimming pool in Bordeaux. He was my diving instructor, and we started to discuss science. He was a university professor involved in food and environmental toxicology; I was a young CNRS researcher finishing my Ph.D. in organic geochemistry. We spent many hours talking about our specific thoughts and experiences in our distinct disciplines. This diving classroom was the starting point of a very long collaboration and friendship. Very rapidly, Jean-François introduced me to his national and international networks both in food and environmental toxicologies. During more than 25 years, we have shared joint research projects, chaired the coordination of several European research projects on fate and effects of pollutants in marine animals, and finally set the foundations of a unique and interdisciplinary research unit at the University of Bordeaux, combining environmental toxicology and chemistry. We share a lot of memories: sampling and diving cruises both in freshwater lakes and in the seas, brain-storming meetings to write regulations or producing a work program for EU research projects, and also some non-work-related get-togethers and parties with Jean-François playing guitar and singing popular French and international songs.

Jean-François Narbonne has always had a lot of new ideas and new research directions in mind. He has been one of the French pioneers in the PCB story. He also worked on pesticides and dioxins long before they were common scientific topics and in the public awareness. He has always shared his career between research and teaching activities at the University of Bordeaux, as expert in various national and international committees and spokes person for various media outlets (broadcasting, TV, newspapers, conferences), translating science for the general public. He is a prime example of a link among research, regulation and policy, and also the general public.

Jean-François, I must confess that you have positively influenced my scientific career, by training me in toxicology and also in scuba diving! I wish you the very best for the future!!!

\section{References}

Lauby-Secretan B, Loomis D, Grosse Y, El Ghissassi F, Bouvard V, Benbrahim-Tallaa L, Guha N, Baan R, Mattock H, Straif K (2013) Carcinogenicity of polychlorinated biphenyls and polybrominated biphenyls. Lancet Oncol 14(4):287-8. doi:10.1016/S1470-2045(13) 70104-9, PMID: 23499544 